\title{
Resolução de problemas - Uma perspectiva no ensino de matemática
}

\begin{abstract}
Marta Burda Schastai
Sani de Carvalho Rutz da Silva

Maria de Fátima Mello de Almeida

\section{Resumo}

As orientações dos Parâmetros Curriculares Nacionais estão voltadas para a inserção da Resolução de Problemas como eixo articulador entre o conhecimento do aluno e os conhecimentos matemáticos historicamente produzidos. A partir desta orientação organizou-se um Curso de Formação para Professores do 6을 ano da Rede Estadual de Ensino com o objetivo de desenvolver habilidades de escrita e análise de problemas. Portanto, o presente trabalho baseia-se nas atividades desenvolvidas nesse Curso e teve como questão norteadora "Como explorar o Ensino da Matemática a partir da Resolução de Problemas e da prática social dos conteúdos?". Para responder a questão propôsse aos professores que escrevessem e apresentassem problemas a partir de um contexto escolhido pelos grupos. Após apresentação dos problemas analisou-se qualitativamente o problema bem como foram feitas interferências, complementações e/ou readequações. Finalizando, percebeu-se que os professores ampliaram seus conhecimentos em relação à escrita e resolução de problemas em uma perspectiva metodológica.
\end{abstract}

Palavras-chave: resolução de problemas, perspectiva metodológica, conhecimento matemático.

\section{Abstract}

\section{Troubleshooting- a perspective in mathematics education}

The guidelines of the National Curriculum are focused on the insertion of Troubleshooting central theme of the student's knowledge and mathematical knowledge historically produced. From this orientation was organized a Training Course for Teachers of the 6th year of the State Schools for the purpose of developing writing skills and problem analysis. Therefore, the present work is based on activities in this course and guiding question was "Exploring the Teaching of Mathematics from the Troubleshooting and social practice of the contents?". To answer the question proposed to the teachers to write and present problems from a context chosen by the groups. After presentation of the problems was analyzed qualitatively as well as the problem were made interference, additions and / or where necessary. Finally, it was noticed that teachers increased their knowledge about writing and problem solving in a methodological perspective.

Keywords: troubleshooting, methodological perspective, mathematical knowledge. 


\section{Introdução}

De acordo com os Parâmetros Curriculares Nacionais - PCN (BRASIL, 2001), a partir das reformas ocorridas mundialmente no período 1980/1995, a Resolução de Problemas vem sendo tema de discussão entre os educadores e pesquisadores da área de Matemática.

E, desde então, várias têm sido as orientações didáticas na abordagem deste tema requerendo assim uma reflexão crítica sobre as diferentes concepções para que se possa utilizar a Resolução de Problemas em sala de aula como um procedimento metodológico que possibilite ao aluno aprender conceitos, ideias e algoritmos matemáticos.

Partindo do princípio de que os conhecimentos matemáticos dos alunos são ampliados a partir de situações-problema, e de que quando há uma questão para ser resolvida é que se buscam resposta possibilitando o processo investigativo, justifica-se a importância da abordagem da Resolução de Problemas do ensino da Matemática.

Sob este contexto, o presente artigo apresenta como caminho para "fazer matemática" em sala de aula, a Resolução de Problemas. A pesquisa foi realizada a partir de um encontro de formação continuada para 40 professores que atuavam na $5 \underline{a}$ série (6o Ano) do Ensino Fundamental da Rede Estadual de Ensino no ano de 2009, abrangendo vários municípios do Estado do Paraná, que pertencem ao Núcleo Regional de Educação de Ponta Grossa.

Nesta formação foram discutidos diferentes aspectos da resolução de problemas, objetivos, estratégias de ensino, encaminhamentos metodológicos e foram realizadas atividades visando à escrita de problemas de forma a exercitar a habilidade dos professores em estruturar enunciados contemplando os diversos tipos de problemas a partir de situações da vida real.

A realização deste trabalho foi norteada pela problemática: “Como explorar o Ensino da Matemática tendo como eixo articulador a Resolução de Problemas e a prática social dos conteúdos?".

O objetivo proposto foi o de desenvolver habilidades de escrita de problemas a partir da exploração de situações do cotidiano das pessoas e da respectiva resolução dos problemas elaborados, tendo como suporte teórico as orientações do PCNs e obras literárias de educadores que se dedicaram ao estudo da Matemática tendo como foco a resolução de problemas. Nesse sentido, buscou-se apresentar como estratégia de ensino a Resolução de Problemas em uma perspectiva metodológica. 


\section{Desenvolvimento}

Nas últimas décadas, a Resolução de Problemas tem sido considerada como uma perspectiva metodológica que substitui métodos de ensino da Matemática que priorizam a repetição e a mecanização.

Gazire (1988, p. 124) defende a Resolução de Problemas como um meio de ensinar Matemática no sentido de que "todo conteúdo a ser aprendido se for iniciado numa situação de aprendizagem, através de um problema desafio, ocorrerá uma construção interiorizada do conhecimento a ser adquirido".

O autor considera que o processo de ensino e aprendizagem inicia-se com o problema, e é pelo desafio de resolver o problema que se dá a aprendizagem, ao mesmo tempo em que, pelas explicações de como pode ser resolvido acontece o ensino.

Este processo sugerido por Gazire (1988) é resultado de várias pesquisas realizadas em relação ao Ensino de Matemática a partir da Resolução de Problemas. Há registros sobre este ensino desde a década de 1940, quando o pesquisador George Polya da Universidade de Stanford dos Estados Unidos lançou sua obra "A Arte de Resolver Problemas" propondo a resolução de problemas em quatro etapas: a primeira, de compreender o problema; a segunda, de elaborar um plano; a terceira, de executar o plano e a quarta etapa a de verificar a solução do problema original. A consecução de uma etapa a outra, formava o processo de resolução (ONUCHIC e ALLEVATO, 2004).

Na década de 1980, o Conselho Nacional de Professores de Matemática - NCTM, que representa uma entidade norte-americana, elaborou o An Agenda for Action - Uma Agenda para Ação, onde colocou a Resolução de Problemas como foco do ensino da Matemática. Seguindo esta recomendação, a reforma da educação ocorrida na década de 1980 no mundo todo apresentou vários pontos de convergência, destacando-se entre eles a "ênfase na resolução de problemas, na exploração da Matemática a partir dos problemas vividos no cotidiano encontrado nas várias disciplinas" (BRASIL, 2001, p. 22).

Na década de 1990 intensificam-se, mundialmente, as discussões sobre a Resolução de Problemas como meio de ensinar Matemática. O problema é considerado como o elemento que desencadeia a construção do conhecimento, e passa a ser definido como "qualquer situação que exija o pensar do indivíduo para solucioná-la" (DANTE, 1991, p. 32).

Entre as décadas de 1990 e 2000 os Parâmetros Curriculares Nacionais, em suas orientações, direcionam a Resolução de Problemas como encaminhamento metodológico para o Ensino Fundamental. A base para esta recomendação é a resolução de problemas vinculados ao cotidiano dos alunos, como por exemplo, "a divisão de terras, cálculo de créditos" (BRASIL, 2001, p. 23). 
Paulatinamente a Resolução de Problemas como perspectiva metodológica vem sendo discutida e aplicada por professores com o intuito de apresentar o ensino por meio de um "sistema de conceitos, que permite resolver um conjunto de problemas" (BRASIL, 2001, p. 43).

Segundo Onuchic e Allevato (2004, p. 222), "ensinar matemática através da resolução de problemas é uma abordagem consistente com as recomendações do NCTM e dos PCNs, pois conceitos e habilidades matemáticos são aprendidos no contexto da resolução de problemas".

Para estas autoras o ensino por meio da Resolução de Problemas significa não apenas resolver problemas, mas sim ensinar a Matemática, pois o problema se torna um ponto central, a partir do qual se constrói o conhecimento. Neste processo o professor tem como função a de formalizar os conceitos e as técnicas operatórias. Assim Onuchic e Allevato (2004, p.228), consideram que,

$O$ ponto central de nosso interesse em trabalhar o ensino-aprendizagem de matemática através da resolução de problemas baseia-se na crença de que a razão mais importante para esse tipo de ensino é a de ajudar os alunos a compreenderem os conceitos, os processos e as técnicas operatórias necessárias dentro do trabalho feito em cada unidade temática.

Há consenso entre os educadores, que quando são apresentados problemas para os alunos encontrarem uma solução, eles conscientizam-se do potencial de seu conhecimento e consequentemente são motivados a "incorporar novos conhecimentos reestruturando os que já têm" (CALLEJO e VILA, 2004, p.170).

Nas orientações dos PCNs (BRASIL, 2001, p. 43), a recomendação de que para superar as dificuldades dos alunos em resolver as questões matemáticas por meio da Resolução de Problemas há necessidade de aplicar nesta proposta metodológica alguns princípios, sendo eles:

- o ponto de partida da atividade matemática não é a definição, mas o problema;

- o problema certamente não é um exercício em que o aluno aplica, de forma quase mecânica, uma fórmula ou um processo operatório;

- aproximações sucessivas ao conceito são construídas para resolver um certo tipo de problema; num outro momento, o aluno utiliza o que aprendeu para resolver outros, o que exige transferências, retificações, rupturas;

- o aluno não constrói um conceito em resposta a um problema, mas constrói um campo de conceitos que tomam sentido num campo de problemas;

- a resolução de problemas não é uma atividade para ser desenvolvida em paralelo ou como aplicação da aprendizagem, mas uma orientação para a aprendizagem. 
Busca-se por meio desses princípios, oportunizar ao aluno, o desenvolvimento do pensamento matemático e introduzir novos conceitos matemáticos que possibilitem conexões com outros aprendizados de forma a ampliar os conhecimentos matemáticos que já possuíam.

Assim, ao ensinar matemática sob a perspectiva da Resolução de Problema, praticam-se novas interpretações para o aprendizado da Matemática. Mendonça (1993), por exemplo, indica três interpretações para o ensino e aprendizagem a partir da resolução de Resolução de Problema.

A primeira interpretação é conceber o ensino e aprendizagem como um objetivo, que significa ensinar Matemática para resolver problemas, sendo que a resolução é a meta final. A segunda interpretação é conceber como um processo, em que a Resolução de Problemas é uma forma de desenvolver o potencial heurístico do aluno, colocando seu desempenho como característica de sua condição de resolvedor. A terceira interpretação é conceber o problema como um ponto de partida, entendendo-o como elemento que pode desencadear a construção do conhecimento matemático.

Há também o estudo de Smole e Diniz (2001, p.89) que concebem a Resolução de Problemas numa Perspectiva Metodológica como "um modo de organizar o ensino o qual envolve mais que aspectos puramente metodológicos, incluindo uma postura frente ao que é ensinar e, consequentemente, do que significa aprender".

As autoras consideram uma forma de ensinar que contempla o processo investigativo a partir de situações convencionais ou não convencionais, como por exemplo, jogos, atividades planejadas, seleção de informações, objetivando complementar a resolução de problemas tradicionais, propondo situações-problema e resolvendo situações propostas pelas ações de questionar as respostas obtidas e a própria situação inicial.

Nesta concepção, considera-se que pela metodologia da Resolução de Problemas desenvolve-se no aluno uma atitude de investigação científica em relação ao que está posto. Quando o aluno questiona as soluções e a situação-problema em si, volta a uma atividade já realizada, sob um novo pensar sobre a situação num processo metacognitivo, ou seja, pensando sobre o que já pensou ou fez.

Smole e Diniz (2001) afirmam que este pensar exige raciocínio e ao mesmo tempo, possibilita ao aluno ampliar o conhecimento por meio das relações que estabelece entre o que sabe e o que está aprendendo. Neste processo, a curiosidade, a iniciativa, a investigação e a confiança, em suas próprias ideias, passam a ser valorizadas melhorando a autoestima.

As autoras ainda afirmam que os problemas têm como objetivo alcançar um conteúdo, sendo este, considerado como o conhecimento historicamente produzido, incluindo as habilidades necessárias para garantir a formação de pessoas independentes, confiantes em seu 
saber, capazes de entender e usar os procedimentos e regras próprias da área do conhecimento proporcionando a formação integral do aluno.

A partir dessas preposições torna-se relevante conduzir o Ensino de Matemática na perspectiva metodológica da Resolução de Problemas e, para tanto, é necessário que o professor esteja em constante formação aprimorando, aperfeiçoando e aprofundando seus conhecimentos para promover estratégias de ensino voltadas para a resolução de problemas relacionados com as situações do cotidiano das crianças.

\section{Avaliando a escrita de problemas relacionados com o cotidiano das crianças}

\subsection{Encaminhamento metodológico}

Realizou-se a investigação deste estudo pela ordem qualitativa, considerando as orientações de Garnica (2004) quando explica que uma pesquisa qualitativa apresenta transitoriedade nos resultados; não permite a neutralidade do pesquisador, possibilitando que ele interprete as perspectivas e filtros vivenciais prévios, reconfigurando compreensões e os meios de obtê-las. À medida que o estudo foi avançando priorizaram-se os procedimentos descritivos com algumas interferências subjetivas.

As atividades foram realizadas em um contexto dinâmico e participativo percebendo-se com intensidade a compreensão dos sujeitos envolvidos no processo de construção do conhecimento.

Iniciou-se o encontro de formação de professores com a retrospectiva histórica da Resolução de Problemas, concepções, encaminhamentos metodológicos e objetivos explicitandose também a pretensão de percorrer um "caminho para fazer matemática" em sala de aula por meio de atividades que visavam o aprendizado de como elaborar enunciados de problemas.

$\mathrm{Na}$ sequência os professores cursistas se organizaram em grupos, o professor coordenador da Oficina disponibilizou fichas com instruções para elaboração de problemas e cada grupo escolheu uma das fichas de acordo com a afinidade que tinha com o tema.

De acordo com instruções das fichas, cada grupo de professores cursistas elaborou problemas buscando explorar algum conceito ou conteúdo e relacioná-lo com a prática social. Durante a realização dessa atividade o professor coordenador da Oficina foi chamado pelos cursistas para esclarecer dúvidas, fazendo várias interferências, questionando os professores quanto à linguagem, clareza, objetivo, conceitos contemplados nos problemas por eles escritos.

Concluiu-se o encontro de formação com a apresentação dos problemas elaborados pelos professores nos grupos, análise dos enunciados, contribuições dos demais professores para reestruturação dos problemas quando necessários e avaliação dos mesmos quanto a sua 
aplicabilidade.

\subsection{Público-alvo e material utilizado}

O estudo foi realizado com 40 professores que atuavam na 5 a série (60 Ano) do Ensino Fundamental da Rede Estadual de Ensino, em um Curso de Formação Continuada, abrangendo vários municípios do Estado do Paraná que pertencem ao Núcleo Regional de Educação de Ponta Grossa.

O material utilizado na formação constou de cartelas de papel cartão com frases que indicavam a elaboração de um problema a partir de determinado contexto, folhas de papel sulfite, transparências, lápis, caneta, borracha, canetinhas para transparência, giz, quadro e retroprojetor. Esse material foi disponibilizado pelo professor coordenador da Oficina.

\subsection{Resultados e discussões}

O início do trabalho se deu com a escolha de uma cartela por grupo de acordo com o contexto que se identificavam. Foi decidido pelos professores que a quantidade de problemas a ser apresentada no grande grupo, em resposta a instrução contida na cartela, seria de um problema por grupo quando semelhantes ou mais quando tratassem de diferentes conceitos. Portanto, não seriam apresentados problemas semelhantes para evitar dupla discussão, anulando-se por consenso do grupo aqueles enunciados semelhantes, sendo escolhido para apresentação apenas um problema para cada conceito.

Os grupos tinham a opção de escrever a quantidade de enunciados que achassem convenientes não sendo necessário que todos elaborassem um enunciado. Considerou-se aqui, o trabalho participativo e integração das ideias.

Cada grupo, assim como cada cartela foram denominados pelas letras do alfabeto para facilitar a avaliação e discussão dos resultados. Portanto, o grupo A ficou com a cartela A, o grupo B com a cartela B e assim sucessivamente até o grupo $\mathrm{G}$ que ficou com a cartela $\mathrm{G}$.

Na sequência disponibiliza-se a apresentação do resultado e a discussão de cada caso. 
3.4.1 Grupo A - cartela A

O grupo A escolheu a cartela aqui denominada de $A$ com a seguinte instrução:

ELABORE UM PROBLEMA

UTILIZANDO AS PÁGINAS DOS CLASSIFICADOS

Seguido de uma discussão de qual seria o melhor enunciado, os professores apresentaram o seguinte problema:

William foi à loja escolher presente para o Lia da Crianga. Ele gostou de uma bola $R \$ 20,00$ e um custava $R \$ 18,00$.

Este enunciado aproxima o problema com a vivência do aluno, considerando que os elementos escolhidos (bola e cachorrinho) geralmente fazem parte do cotidiano das crianças e que os seus valores são os praticados no comércio. Cândido (2001, p. 14) considera a necessidade de uma comunicação no ensino de Matemática, onde se relaciona a escrita com a vivência, ajudando "os alunos construírem um vínculo entre suas noções informais e intuitivas e a linguagem abstrata e simbólica da matemática".

Além de se estabelecer a relação entre a vivência dos alunos e a linguagem escrita, com esse problema é possível desafiar o aluno na tomada de decisão quanto aos procedimentos a serem adotados para se obter a resposta, proporcionando a mobilização de conhecimentos anteriores.

O aluno é desafiado a buscar conceitos e algoritmos já aprendidos para resolver o problema e obter como resposta não um número, mas a escolha do brinquedo que se adapta nas condições de pagamento propostas no enunciado.

R. B. E. C. T., vol 5, núm. 3, set-dez.2012 ISSN - 1982-873X

59 
Outro problema apresentado pelo grupo A foi o seguinte:

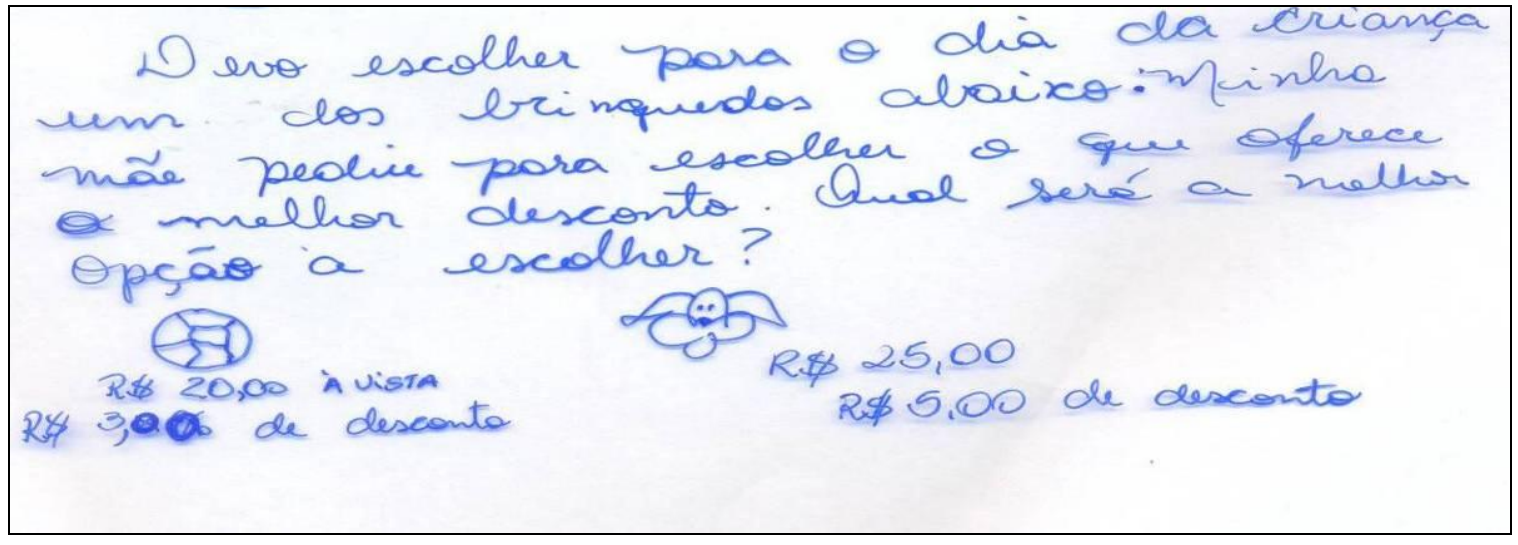

Na elaboração desse problema, os professores buscaram utilizar uma linguagem simples e clara com elementos relacionados ao tema "Dia da Criança" e brinquedos comuns aos folguedos das crianças.

Percebe-se que, para a resolução desse problema se faz necessário o cálculo da porcentagem, que é um conteúdo a ser trabalhado no 6ㅇ ano do Ensino Fundamental e que não está evidente no enunciado, é necessário que se faça a leitura, interpretação e os cálculos matemáticos para então tomar a decisão quanto à resposta certa de acordo com as condições estipuladas no enunciado do problema.

É importante, propor para as crianças diversos tipos de problemas, para que elas não definam problema como sendo a resolução de algoritmos, treinamento de operações matemáticas ou respostas numéricas, mas sim aprendam como resolver os problemas que lhes são apresentados no dia-a-dia.

\subsubsection{Grupo B - cartela B}

O grupo B escolheu a cartela aqui denominada de B com a seguinte instrução:

\section{ELABORE UM PROBLEMA}

\section{QUE ENVOLVA O SISTEMA MONETÁRIO}

Para o grupo B foram disponibilizados panfletos de supermercados e lojas. Ao propor o uso de panfletos na elaboração de problemas envolvendo o sistema monetário o objetivo foi proporcionar aos professores o trabalho com problemas da vida real, relacionando a matemática da vida com a matemática escolar. O primeiro problema apresentado pelos professores refere-se à compra de bonés, conforme segue: 


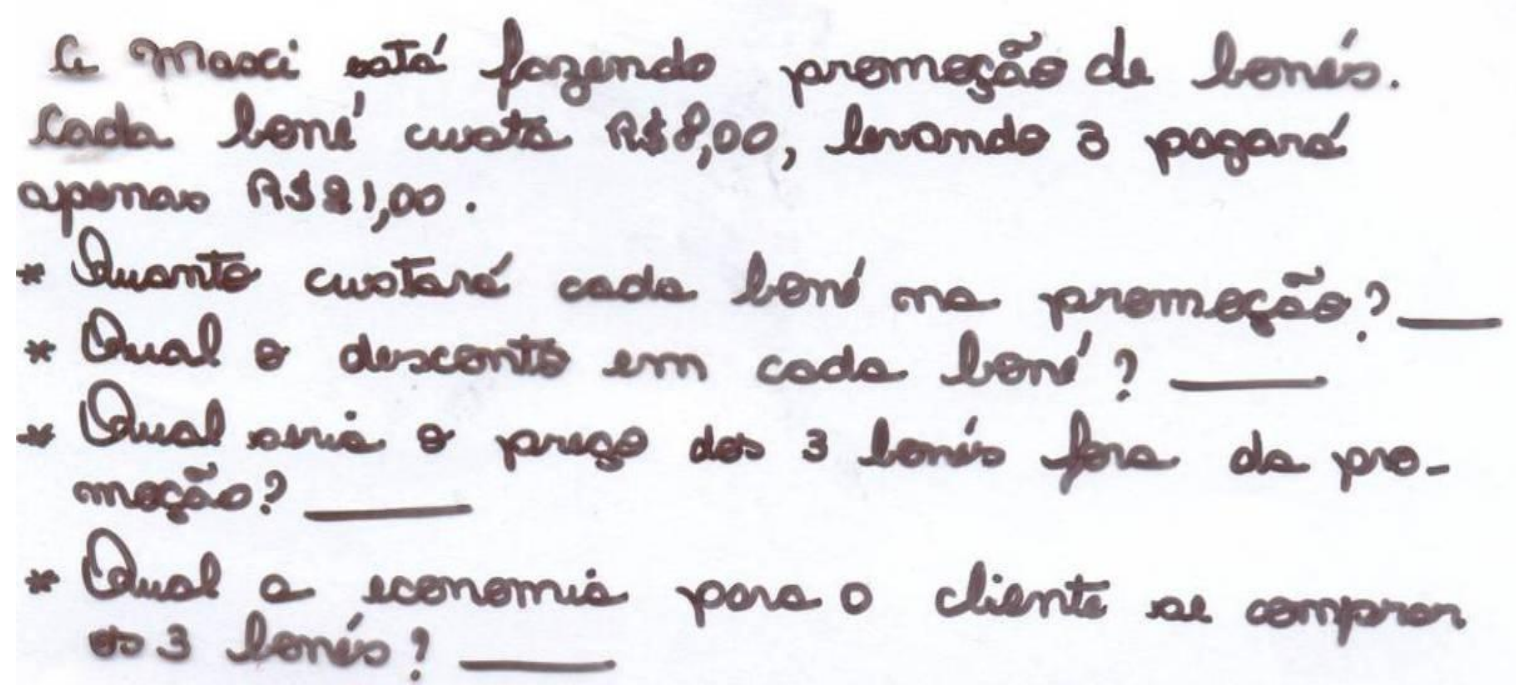

Observa-se que o problema contempla uma situação que pode ser vivenciada no cotidiano das pessoas e que envolve a tomada de decisão quanto aos cálculos matemáticos a serem adotados para se obter as respostas. Segundo os PCNs (BRASIL, 2001, p. 44), "um problema matemático é uma situação que demanda a realização de uma sequência de ações ou operações para obter um resultado", portanto cabe ao resolvedor construir a solução.

Nesse caso as respostas são numéricas e envolvem as operações de divisão, subtração e multiplicação podendo ser realizadas por meio do cálculo mental. Abrantes (2001) explica que as destrezas com o cálculo mental proporcionam e desenvolvem a compreensão numérica dos alunos, pois são forçados a buscar as propriedades dos números e das operações para encontrar a melhor solução.

\subsubsection{Grupo C - cartela C}

O grupo $C$ escolheu a cartela aqui denominada de $C$ com a seguinte instrução:

\section{ELABORE UM PROBLEMA \\ UTILIZANDO A PÁGINA DE ESPORTES DE UM DOS JORNAIS}


Após discussão entre os professores do grupo $\mathrm{C}$ foram escolhidos dois problemas para serem apresentados aos demais colegas. O primeiro problema a ser apresentado foi:

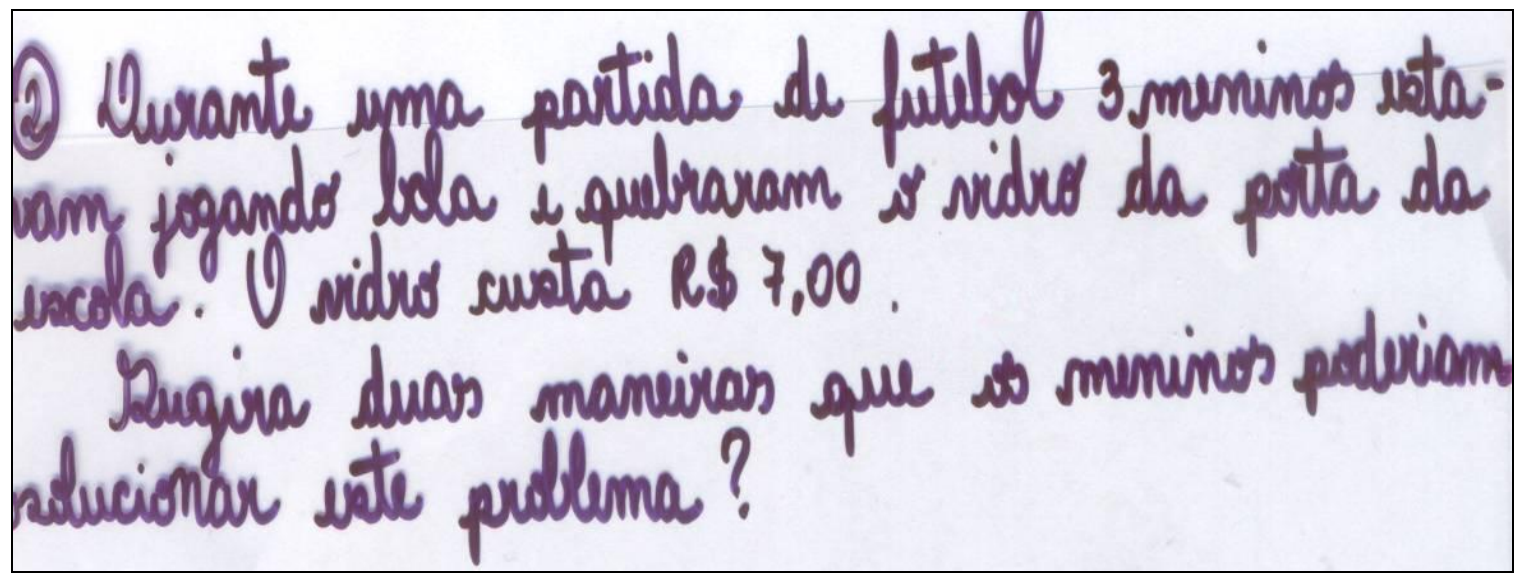

Ao se propor problemas que não exigem como resposta um único dado numérico possibilita-se aos alunos desenvolver a habilidade de propor diversas soluções, análise, e tomada de decisão por uma resposta que seja a mais apropriada para o contexto. De acordo com Dante (2009, p.26) esses problemas,

...aguçam a curiosidade do aluno e permitem que ele desenvolva a criatividade, a iniciativa e o espírito explorador. E, principalmente, iniciam o aluno no desenvolvimento de estratégias e procedimentos para resolver situaçõesproblema, o que, em muitos casos, é mais importante que encontrar a resposta certa.

Em situações abertas como a que se apresenta envolve-se além dos conhecimentos matemáticos os temas transversais mencionados nos PCNs, como valores e ética. Segundo orientações dos PCNs, as aulas de matemática podem ser direcionadas para desenvolver atitudes éticas no aluno, como no exemplo, a atitude do aluno em arcar ou não com a conseqüência de quebrar um vidro da escola, e ao mesmo tempo impulsionando-o à realização de um cálculo matemático.

O segundo problema apresentado pelo grupo C contempla a estimativa, conforme se visualiza a seguir:

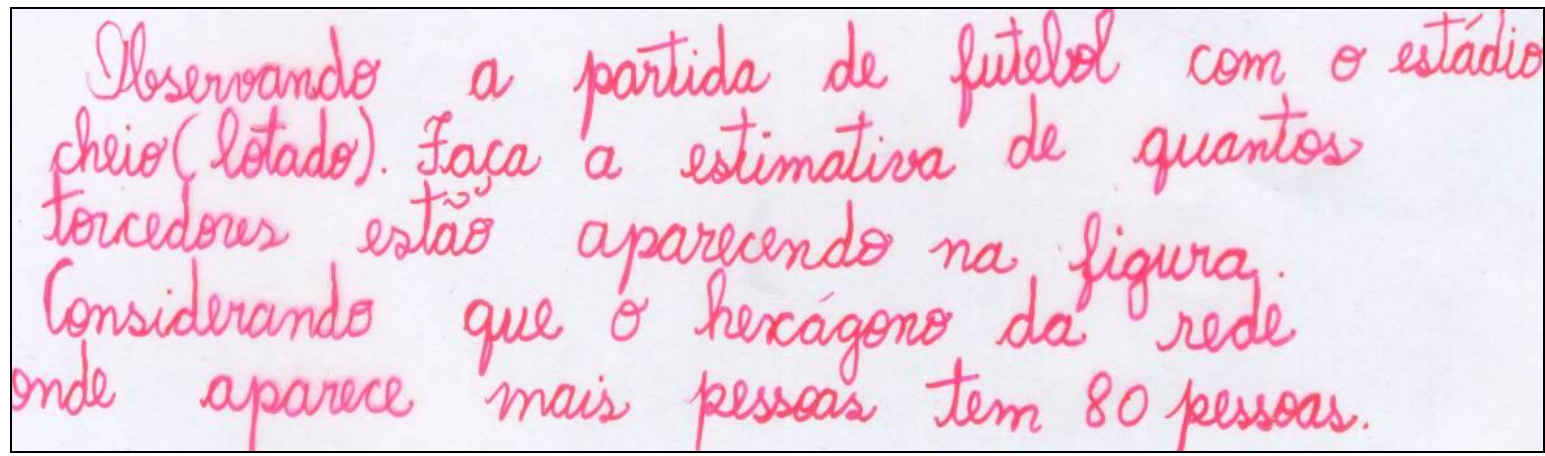


Analisando-se o enunciado da questão elaborada pelos professores percebe-se o uso da linguagem matemática por meio do termo hexágono referindo-se a forma da malha em que a rede foi construída, relacionando a definição matemática com as formas geométricas encontradas no cotidiano e a estimativa dentro de um contexto real, em consonância com o posicionamento de Dante (2009, p.51) quando alerta que "problemas com dados e perguntas artificiais desmotivam o aluno".

O enunciado do problema favorece a identificação de formas, medidas de superfícies, quantificação por meio de estimativas e possibilita ao aluno aprender a refinar suas habilidades para cálculo matemático (BRASIL, 2001, p. 119).

\subsubsection{Grupo D - cartela D}

O grupo $D$ escolheu a cartela aqui denominada de $D$ com a seguinte instrução:

\section{ELABORE UM PROBLEMA}

\section{A PARTIR DE UM ANÚNCIO}

Após discussão entre os professores do grupo $D$ foram escolhidos dois problemas para serem apresentados aos demais colegas. $O$ primeiro problema a ser apresentado foi:

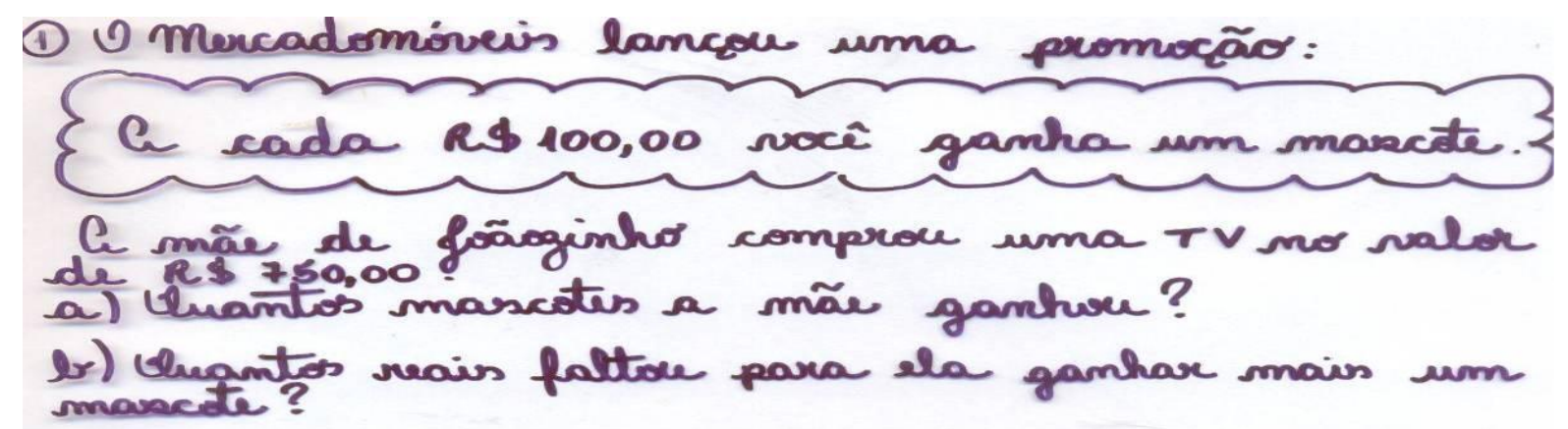

E o segundo problema, elaborado a partir do valor estipulado de compra necessário para ganhar a mascote foi:

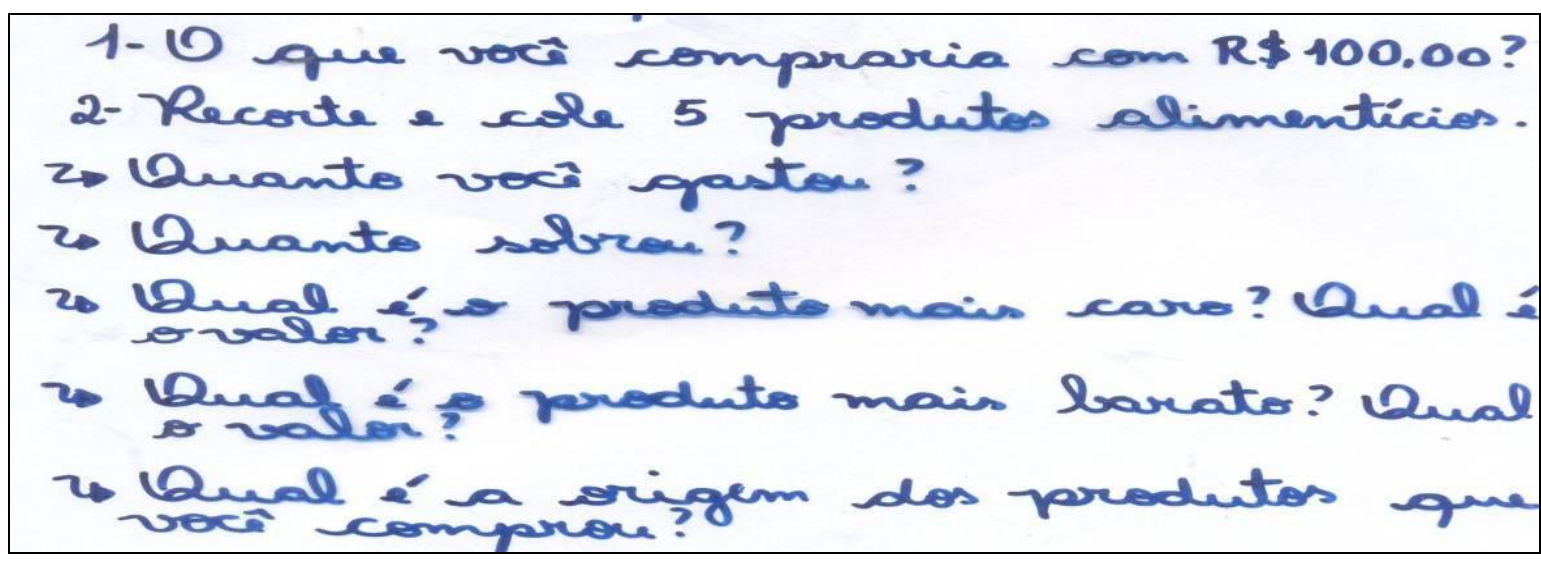


Em ambos os problemas percebe-se que os dados são reais. O primeiro problema possibilitou os questionamentos: "Por que com 50 reais de compra não é possível trocar por uma mascote?", "Como funcionam os arredondamentos na prática?" e o segundo problema favoreceu a interdisciplinaridade ao levantar a questão da origem dos produtos adquiridos. Assim, foram elaborados em consonância com as orientações de Dante (2009, p.51) quando afirma que "os dados de um problema precisam ser reais, quer nas informações, quer nos valores numéricos apresentados".

\subsubsection{Grupo E - cartela E}

O grupo $E$ escolheu a cartela aqui denominada de $E$ com a seguinte instrução:

\section{ELABORE UM PROBLEMA}

\section{A PARTIR DE UMA TABELA}

O grupo selecionou um problema para apresentar aos demais colegas, conforme se visualiza a seguir:

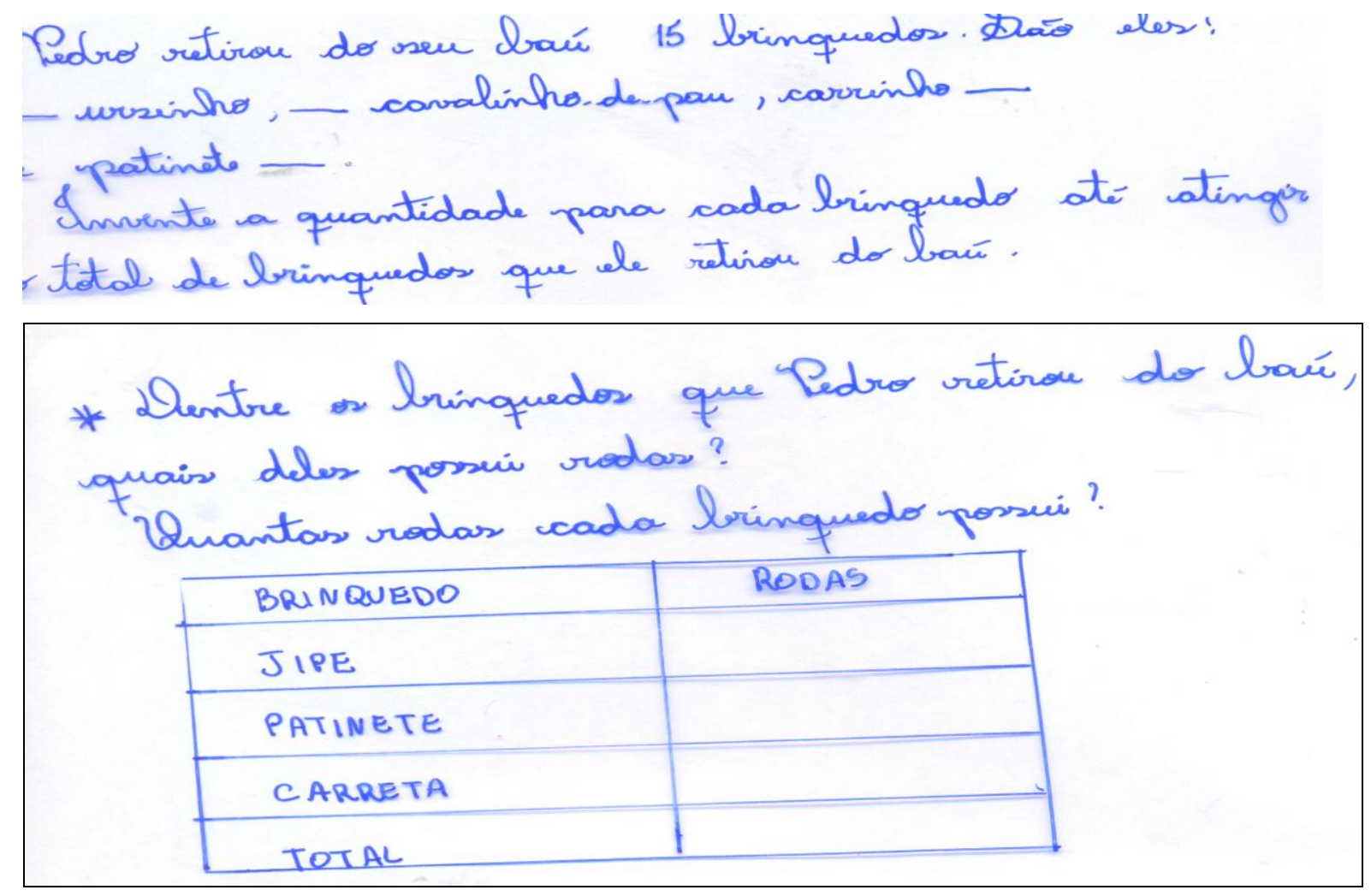

De acordo com Dante (2009, p. 22), um dos principais objetivos da matemática no ensino fundamental é o de "aprofundar o pensamento e liberar a criatividade", ações essas que podem ser desenvolvidas "por meio da formulação e da resolução de problemas que exijam o pensamento produtivo do aluno". 
Nesse sentido, propor problemas em que os alunos precisam completar com dados que faltam é uma das maneiras de se proporcionar o desenvolvimento da criatividade, no entanto, Dante $(2009$, p. 22) alerta que o problema por "si só não garante o desenvolvimento da criatividade, mas aumenta a possibilidade de ela se manifestar".

\subsubsection{Grupo F - cartela F}

O grupo $\mathrm{F}$ escolheu a cartela aqui denominada de $\mathrm{F}$ com a seguinte instrução:

\section{ELABORE UM PROBLEMA}

\section{QUE ENVOLVA SISTEMA DE MEDIDAS}

O grupo selecionou um problema para apresentar aos demais colegas, conforme se visualiza a seguir:

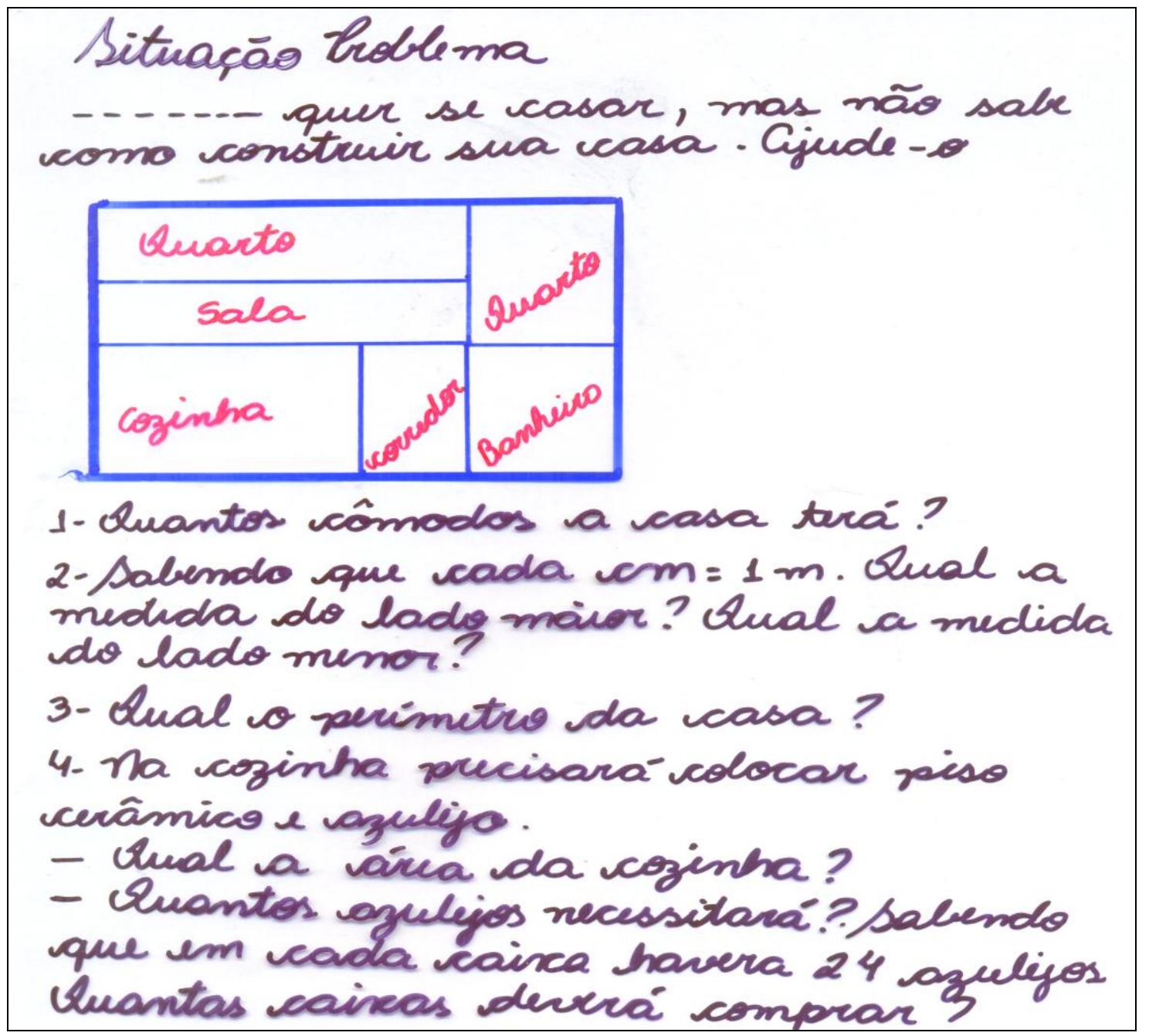


Analisando-se o problema elaborado pelo grupo $\mathrm{F}$ percebe-se que está de acordo com a instrução contida na ficha. No entanto é um problema-padrão e de acordo com Dante (2009, p. 25),

Sua resolução envolve a aplicação direta de um ou mais algoritmos anteriormente aprendidos e não exige nenhuma estratégia. A solução do problema já está contida no próprio enunciado, e a tarefa básica é transformar a linguagem usual em linguagem matemática, identificando as operações ou algoritmos necessários para resolvê-lo.

Esse tipo de problema tem como função recordar e fixar conceitos aprendidos, conforme se visualiza na pergunta "Qual o perímetro da casa?", porém não desenvolve a criatividade nem desencadeia o desejo em resolvê-lo. É um enunciado que não se enquadra na perspectiva metodológica da Resolução de Problema.

Uma das sugestões dadas pelos colegas ao grupo $\mathrm{F}$ refere-se à proposição de enunciados de problemas que possibilitassem ao aluno a realização de medidas tanto de comprimento quanto de superfície.

\subsubsection{Grupo G - cartela G}

O grupo $\mathrm{G}$ escolheu a cartela aqui denominada de $\mathrm{G}$ com a seguinte instrução:

\section{ELABORE UM PROBLEMA}

\section{RELACIONADO À DISTRIBUIÇÃO DE DADOS COLETADOS}

O grupo selecionou um problema para apresentar aos demais colegas, conforme se visualiza a seguir:

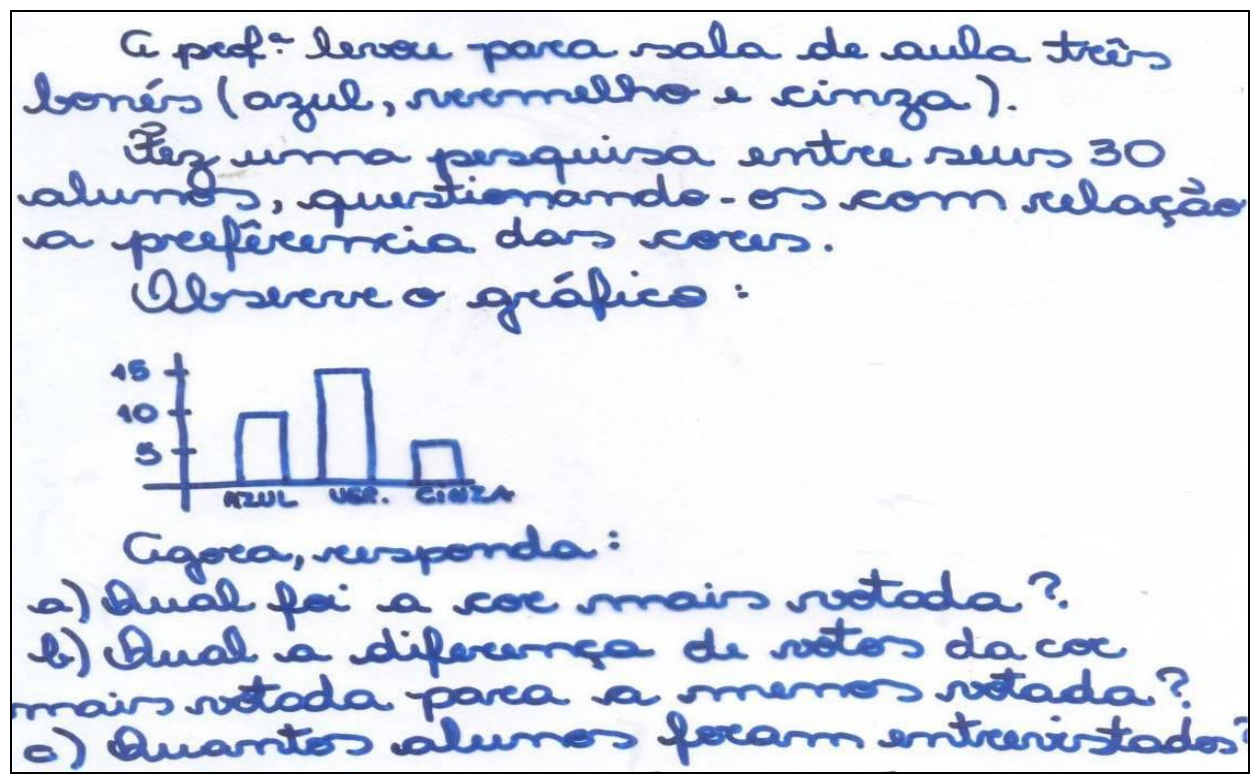


O problema elaborado pelo grupo $E$, novamente retrata um problema do tipo padrão e não requer a investigação matemática. Alguns professores sugeriram a elaboração de um problema que proporcionasse aos alunos a pesquisa em relação à preferência das cores dos bonés com os alunos da turma e depois com os alunos da escola. A partir dos dados organizassem uma tabela e construíssem um gráfico de setores com as frequências absolutas e outro com a frequência relativa e fizessem a comparação.

De acordo com Dante (2009, p.21), a aula de Matemática deve ser aquela, ..., na qual os alunos, incentivados e orientados pelo professor, trabalhem de modo ativo - individualmente ou em pequenos grupos - na aventura de buscar a solução de um problema que os desafia é mais dinâmica e motivadora do que a que segue o clássico esquema de explicar e repetir.

Portanto, ao se propor um problema é necessário que o professor tenha claro porque propôs e quais habilidades deseja trabalhar não esquecendo que "o real prazer de estudar matemática está na satisfação que surge quando o aluno, por si só, resolve um problema" (DANTE, 2009, p.21).

Ainda, de acordo com os PCNs o processo de ensino e aprendizagem de Matemática na perspectiva de Resolução de Problemas possibilita o trabalho voltado para a compreensão dos diferentes significados que cada conceito matemático pode apresentar, usando para tanto um estudo reflexivo do cálculo em diferentes matizes: exato ou aproximado, mental ou escrito. (BRASIL, 2001), o que pode gerar a satisfação e constituir-se em um desafio para que os alunos possam estar cada vez mais motivados a aprender Matemática.

\section{Conclusão}

Analisando os problemas escritos pelos professores no que se refere à aproximação dos conteúdos escolares com a prática social percebe-se que os grupos $A, B, C$ e D, que tiveram como material de apoio jornais e/ou panfletos, não encontram dificuldades em utilizar dados reais dentro de um contexto social para escrever os problemas.

Os grupos F e G que não utilizaram material de apoio elaboraram problemas explorando conceitos matemáticos sem relacionar com a prática social, tendo como parâmetro, problemas padrão apresentados nos livros didáticos.

O grupo E não tinha material de apoio disponível e diante da dificuldade em escrever enunciados de problemas a partir do contexto indicado na ficha $E$, por iniciativa própria emprestaram panfletos de outros grupos e a partir dos mesmos elaboraram um problema interessante que desafia os alunos a completarem uma tabela com dados possibilitando as discussões em sala de aula desenvolvendo a oralidade e a argumentação dos alunos, visto a grande quantidade de respostas possíveis. 
Assim, os professores ao criarem seus próprios problemas precisaram mobilizar os conhecimentos matemáticos prévios relacionando-os com a estrutura de escrita de textos para que pudessem comunicar o que pretendiam, demonstrando também o que entendiam por problemas relacionados com a prática social.

Portanto, buscou-se neste trabalho fazer a aproximação entre o conteúdo matemático escolar e o seu uso em situações do cotidiano de acordo com os PCNs que orientam quanto ao encaminhamento metodológico no sentido do professor em suas aulas relacionar os algoritmos matemáticos escolares com a aplicabilidade por meio da Resolução de Problemas. Também houve a intenção de mostrar que se pode aprender Matemática com problemas vinculados a situações da prática social, de modo que a disciplina deixe de ser vista como necessária apenas para alguns intelectuais e ao mesmo tempo, deixe de ser a causa da desistência da escola.

Os professores ao escreverem os problemas perceberam que, eles próprios encontraram dificuldades na escrita dos enunciados, portanto, essa situação possibilitou a reflexão dos mesmos sobre os encaminhamentos dados aos conteúdos em sala de aula, os objetivos das atividades propostas, o tipo de formação que se deseja para as crianças e adolescentes nessa era das tecnologias e da comunicação e sobre a Resolução de Problemas na perspectiva metodológica.

Conclui-se que o professor pode, em sala de aula, propor atividades aos alunos de forma a inserir os conteúdos matemáticos sob um contexto amplo que foge do sistema mecanizado, proporcionando que o aluno relacione o conteúdo abordado em sala com as práticas desenvolvidas e observadas fora da escola.

\section{Referências}

ABRANTES, P. Avaliação e educação matemática. Rio de Janeiro: MEM/USU/GEPEM, 2001. Série Reflexões em Educação Matemática.

BRASIL, Ministério da Educação. Secretaria da Educação Fundamental. Parâmetros Curriculares Nacionais: Matemática (1aa a ạ série). 3. ed. Brasília: Secretaria da Educação, 2001.

CALLEJO, M. L.; VILA, A. Matemática para aprender a pensar: o papel das crenças na resolução de problemas. Porto Alegre: Artmed, 2004.

CANDIDO, P. T. Comunicação em matemática. In: SMOLE, K. S.; DINIZ, M. I. (orgs.). Ler, escrever e resolver problemas - habilidades básicas para aprender matemática. Porto Alegre: Artmed, 2001, p. 15-28.

DANTE, L. R. Didática da Resolução de Problemas de Matemática. 2. ed. São Paulo: Ática, 2009. 
GARNICA, A. V. M. História oral e educação Matemática. In: BORBA, M. C.; ARAÚJO, J. L. (orgs.) Pesquisa qualitativa em Educação Matemática. Belo Horizonte: Autêntica, 2004.

GAZIRE, E. S. Resolução de Problemas: perspectivas em Educação Matemática. 150f., 1988. Dissertação (Mestrado em Educação Matemática), Rio Claro: UNESP.

MENDONÇA, M. C. D. Problematização: um caminho a ser percorrido em Educação Matemática, 280f., 1993. Tese (Doutorado em Educação). Campinas: UNICAMP.

ONUCHIC L. R.; ALLEVATO, N. S. G. Novas reflexões sobre o ensino-aprendizagem de matemática através da Resolução de Problemas. In: BICUDO, M. A.; BORBA, M. (orgs.) Educação Matemáticapesquisa em movimento. São Paulo: Cortez, 2004.

SMOLE, K. S.; DINIZ, M. I. Ler, escrever e resolver problemas. Porto Alegre: Artmed, 2001.

Marta Burda Schastai. Secretaria Municipal de Educação de Ponta Grossa - SME. Colégio Estadual Professora Linda Salamuni Bacila. martaschastai@gmail.com

Sani de Carvalho Rutz da Silva . Universidade Tecnológica Federal do Paraná Campus Ponta Grossa - UTFPR. sani@utfpr.edu.br

Maria de Fátima Mello de Almeida. Secretaria Municipal de Educação de Ponta Grossa - SME. fatiall@bol.com.br 